\title{
FLUXUS SOB MUSEU. AINDA HÁ ARTE E VIDA NESTA HISTÓRIA?
}

Ana Paula Felicissimo de Camargo Lima

Doutoranda em História da Arte pelo IFCH - UNICAMP e Bolsista CNPq

"Toda comunicação é uma collage."”

Os festivais e performances do Grupo Fluxus, durante os anos de 1960 e 1970, promoviam Arte e Vida indissociáveis acreditando que toda atividade cotidiana poderia se tornar um ato Fluxus. Para tal, sob a batuta do lituano George Maciunas e influências do Dadaísmo, Futurismo, Marcel Duchamp, Zen Bubismo e Grupo Gutai, um coletivo de artistas realizou, em locais diferentes das instituições, galerias e museus com suas amarras legitimadoras, propostas embasadas em ações cotidianas que podiam ser realizadas/ repetidas por qualquer pessoa chamando-as Fluxus. Acreditavam em uma arte social e verdadeiramente democrática, independente dos valores preconcebidos ou impostos pelo sistema e mercado ligado à Arte.

Alguns desses artistas estudaram com John Cage no Black Mountain College e na New School for Social Research, herdando assim a congruência e contaminação entre arte, música, dança, teatro e outros meios de expressividade poética. Apoiaram-se também num processo criativo no qual à espacialidade e temporalidade somava-se sobretudo a participação; onde forças interagiam - lembremos aqui a complementaridade de som e silêncio apontada por John Cage em sua peça 4'33" - para uma plenitude entre cheio e vazio combinado em variado gradiente, como as energias Yin e Yang presentes na concepção oriental da vida.

Para evidenciar atos cotidianos como artísticos e a inexistência de fronteiras entre Arte, Música, Poesia e Teatro, houveram os concertos Fluxus. A própria inauguração das atividades Fluxus aconteceu durante Festival Fluxus de Música Nova Novíssima num auditório de Wiesbaden (cidade balneária alemã, distante do eixo Paris - New York) com apresentações, que contando com contribuições do acaso, ocorreram baseando-se nas

1 Declaração de Johannes Cladders sobre o início do Fluxus em entrevista a Gabriele Knasptein, 7 novembro 1994. (In: ZELLER, Ursula (org.). Fluxus in Germany 1962 - 1994. A long tale with many knots. (Textbook). Stuttgard: The Institut für Auslandsbeziehungen, 2005. p.6). 
diretrizes de fichas (parecidas com partituras) por quatro finais de semana de 1962. Alguns dos concertos também incluíram a participação do público presente. Lançaram-se em acontecimentos sob os auspícios da Nova Música, indicando quão necessário era um novo processo criativo no qual, assim como a música, existesse enquanto sua própria apresentação e seu tempo de realização.

Evidenciando o acontecimento como a própria obra de arte inclusive por meio de textos e registros, os artistas-fluxus apoiávam-se num diálogo aberto e sempre em transformação, conduzindo uma dinâmica parecida a de um laboratório onde a experiência e transformação intermitentes estavam exaltadas. O filósofo Arthur Danto coloca que o Fluxus não se resume a sua materialidade mas está ligado à percepção de algo que vemos como arte.

A maioria das obras Fluxus pareciam informais acontecendo em colaboração entre artistas e público, de autoria coletiva e participativa que envolveu diversas disciplinas e nacionalidades. Trabalhando juntos, buscaram a expansão e divulgação de suas críticas e conceitos. Talvez o binômio "arte e antiarte" seja sua constante tensão e gênese indicando processos de transformação e educação a cada um de seus eventos.

Através de concepções que valorizavam a experiência, o processo, a participação e prática artísticas em detrimento ao objeto de arte tradicional. Seu olhar crítico relacionava-se à sociedade e à vida ou à necessidade de discutir os limites do mundo da arte, propondo ser um ato filosófico de experiência que tomara por ventura a forma de arte.

Pensar a produção Fluxus e estes concertos expositivos como manifestações propositalmente abertas, onde não existiriam barreiras separando artistas, arte e público, seja algo exemplar para se manter de modo ampliado as concepções sobre a produção artística bem como seu estudo. Como um local de dúvidas, de encontros e comparações entre linguagens e informações, suas obras, exposições e propostas questionadoras e não habituais à Arte, levam ao exercício de se pensar a Arte e sua História, mas também os museus de arte contemporânea e suas relações de poder e memória.

Fluxus criou mecanismos próprios de registrar sua história. George Maciunas fez árvores genealógicas indicando tanto as raízes do movimento bem como suas ramificações. Em manifestos, textos, revistas e cartas enviadas aos membros do coletivo (não limitadas a este círculo de correspondência, mas sim sob envio postal em estrutura rizômica, como de uma 'corrente', para aumentar a difusão das idéias de uma nova Arte e 
processo criativo), o próprio Fluxus indicou seu lugar (e importância) autolegitimando-se de modo independente dos extratos instituídos pelo sistema.

Percebemos a preocupação em marcar seu terrítorio de atuação, reflexões e conquistas bem como seu testemunho (George Maciunas chegou a designar Ken Friedman, artista mais jovem do grupo, a ser quem escreveria a história do Fluxus). Algumas de suas obras, como os 'Fluxkits' ou as caixas contendo elementos que por manipulação, atingiam os conceitos do trabalho/ação e da produção coletiva, trazendo a reverência à performance ou ao ato cotidiano e simultaneamente ofereceram certa alternativa de perenidade aos elementos (muitos deles industrializados ou impressos de pequena dimensão onde as instruções do fazer estavam apontadas). Podemos enxergar nessas obras a soma de dinâmicas ligadas ao conceito de obra aberta, a presença do entorno (seja indicada pela reprodução; seja pela escolha do material e instruções contidos nos kits) sem limitá-lo a contextualizações diacrônicas e a importância de instruções dadas pelos artistas.

Este acúmulo de itens e registros aconteceu primeiramente como resultado da necessidade de fazer com que manifestos, ações e propostas chegassem a outros artistas Fluxus que se encontravam em diferentes países. Essa comunicação e circulação, principalmente via postal e inclusive pela empresa criada por seus membros e denominada "European MailOrder Warehouse" (1963c.)2, ofereceu a reprodução de obras e concertos por diferentes artistas em vários locais, bem como a contribuição e ampliação de propostas - uma vez que, devido a adaptações, algumas obras, fora de seu ponto de origem, eram refeitas de modo particular usando elementos próprios do espaço de apresentação e informações culturais.

Durante intenso período de investigação artística num trabalho coletivo e corporativo de autoria Fluxus, guardaram-se fotografias, descrição de happenings e execução de atos e objetos entre outros; o que faz transparecer certa preocupação com a transmissão dessa produção; muitas imagens apareceram nos próprios cartazes, convites e publicações que produziram ou adentraram em caixas-anuários, correspondência e kits

2 Os procedimentos de envio postal, seja de publicações, caixas ou correspondência Fluxus, apesar de muitas vezes utilizar o correio, sempre tentavam desenvolver um modo alternativo de venda e novos sistemas de distribuição de arte que não se enquadrassem nas usuais formas culturais. Em meados de 1960, diversas lojas Fluxus se espalharam pelos Estados Unidos, França e Paises Baixos. 
que envolviam a manipulação do observador. Em outra categoria, como mecanismos de sua memória, alguns objetos e registros que ficaram como indícios materiais das atividades Fluxus. Guardados pelos próprios participantes e público, posteriormente tais itens foram inseridos em coleções, inclusive de museus, como elementos que oferecem pesquisa e certo conhecimento relacionado a esta produção que desejava ser efêmera e em movimento como ‘a água de um rio' - daí seu nome.

Esses resíduos materiais de atos Fluxus permitem certa recuperação de outrora. Porém como manter a essência pulsante de sua gênese e simultaneamente não deturpar os objetivos dos artistas ao criá-las? Como essa produção com fronteiras indefinidas, que não queria ser engolida pelas instituições e cuja condição conceitual é preponderante à material poderá estar em locais onde sua guarda e exibição estão regidos pelos sistemas habituais da Museologia e da História, cujas teorias ainda se apóiam nas categorias convencionais da Arte, sua ordenação por cronologia e estratificação por técnicas herdadas da Academia?

Guardiões da memória e aplicando às obras sob seus cuidados os procedimentos habituais pautados na necessidade de tornar legível (ou educativo) tudo que apresentam, os museus estabelecem o que é digno de ser visto ensinando a seus usuários a ler (e muitas vezes 'como' ler), exercendo tarefa de ativar os testemunhos sociais coletados e conservados ${ }^{3}$. Porém a realização destas tarefas também indica escolhas, mecanismos de poder e quiçá filtros e juízos designados e embasados na perenidade da produção artística. Aplicando frases condutoras que adestram olhares, muitas vezes transformam a arte escrevendo, por metalinguagem, uma história manipulada.

As manifestações artísticas aqui tratadas, concomitantes às alterações sócio-culturais de seu período, reverberavam com muitas indagações e desejos por uma sociedade mais livre e participativa, onde instâncias de poder estavam sendo totalmente revistas ou até abolidas. Deste modo os museus - vistos como instituições cristalizadas, hierarquizantes e conduzidas por poucos - acabaram recebendo críticas, entre as quais indicadas diretamente pelas próprias obras.

3 In: PREZIOSI, Donald. Evitando museocanibalismo. Núcleo Histórico: Antropologia e Histórias de Canibalismos. Catálogo da XXIV Bienal Internacional de São Paulo. São Paulo: Fundação Bienal de São Paulo, 1998. p. 51. 
A função argumentativa dessa produção foi desvendar também outras nuances que as instituições aplicavam no tecido social e em suas práticas com os objetos de arte, afastando-a do objetivo de ser somente item deste local de lazer e deleite como ecoou nos séculos XVIII e XIX (período de formação das Academias e Museus Nacionais). Ao indagar os propósitos desses lugares, incluir o visitante como elemento formal das obras e abolir a necessidade de exposição unicamente em nesses espaços instituídos, os artistas inseriram mais do que pesquisas plásticas às obras. Por meio de colocações conceituais e filosóficas sobre o fazer e usufruir objetos artísticos e do diálogo com o ambiente físico e humano, seus processos poéticos sob a forma de obras de arte tornaram-se instrumentos de constestação, indicando novos caminhos para a Arte e as relações possíveis com seu entorno.

Durante esse período de propostas e revisões, Umberto Eco escreveu seu livro Obra Aberta: Forma e Indeterminações nas Poéticas Contemporâneast indicando uma estrutura de relação fruitiva, na qual "não [é] obra-definição, mas o mundo de relações de que esta se origina; não [é] obra-resultado, mas o processo que preside a sua formação; não [é] obra-evento, mas as características do campo de probabilidades que a compreende"s onde

“[...] a forma torna-se esteticamente válida na medida em que se pode ser vista e compreendida segundo múltiplas perspectivas, manifestando riqueza de aspectos e ressonâncias, sem jamais deixar de ser ela própria. [...] Cada fruição é, assim, uma interpretação e uma execução, pois em cada fruição a obra revive dentro de uma perspectiva original." 6

O fruidor jogava assim um quebra-cabeça e transformava as peças/pistas dadas construindo uma frase artística particular.

Exemplo da aplicação desta abertura é “Le Musée de Ben” (1972) de Ben Vautier. Numa caixa contendo internamente e externamente diferentes objetos, palavras e um texto para ser lido pelo público, deixa transparecer que o trabalho somente ocorre quando o visitante faz articulações (votre lecture) entre os elementos fornecidos. A organização é catalográfica e os itens são dispostos lembrando hábitos e práticas museais,

\footnotetext{
4 Obra lançada em meados de 1958 com o título em italiano "Opera Aperta".

${ }^{5}$ In: ECO, Umberto. Obra Aberta. São Paulo: Editora Perspectiva, 2000 (8a edição). p.10.

${ }^{6}$ Op cit. p.40.
} 
mas pela instrução manuscrita ${ }^{7}$ (localizada em uma das portas da caixa) certa abertura é conferida à obra num processo que proporciona originalidade, autoria compartilhada e multiplicidade ao trabalho.

$\mathrm{O}$ uso de materiais industrializados (assim como os usados por Ben Vautier) por poderem ser substituídos a cada montagem da obra (facilitadores para a execução em locais distintos; uma vez que o trânsito dos trabalhos Fluxus, principalmente dentro e entre Alemanha e Estados Unidos, era intenso) trazem uma dinâmica onde o item original não é preponderante e se privilegia o conceito e participação/ realização da proposta artística. Em "Muito Prazer" (1980/1995) de Takako Saito, sob placas imantadas estão dispostos objetos metálicos provindos do local que recebeu a exposição (ou seja, não originais escolhidos e tocados pela artista) que podem ser manipulados pelo visitante configurando-se a cada participação nova apresentação do conjunto.

A obra de Takako Saito entitulada "Café Teatre” (1993/1995) consiste em instrução sobre ação iniciada quando o público se serve de café (no espaço expositivo há uma mesa, com uma cafeteria em funcionamento e copos, localizada ao lado de cadeiras e mesa onde pedaços de papel e caneta aguardam pelo fruidor) e sentado escreve bilhetes para serem lidos pelos futuros visitantes. A preponderância da ação está acima da condição material, ficando os itens usados a mercê do realizado pelo fruidor a cada exposição. Seguir a instrução é o importante; questionar se o ato de tomar cafezinho e escrever bilhetes é Arte são indicadores das tentativas Fluxus de mesclar Arte e vida.

Os trabalhos Fluxus acima citados, hoje fazem parte do acervo do Institut für Auslandsberiehungen e. V. de Stuttgart (Alemanha) e após 1994 ano de formação dessa coleção - estão em itinerância em exposições nacionais e internacionais. Em 2006, seleção deste conjunto foi exibida no Brasil, respectivamente no Museu Oscar Niemeyer (Curitiba, 19 de abril a 23 de julho) e Instituto Tomie Ohtake (São Paulo, 25 de agosto a 8 de outubro). Numa apresentação baseada em balizas museais (ou seja, obras hibernando trancadas em vitrines e etiquetadas para clara informação ao público), certo hiato transcorreu. Como se não bastasse esse contratempo ligado à materialidade e classificações, muitas vezes essas obras foram abortadas por leituras que trocaram sinestesia por anestesia: o trabalho de

\footnotetext{
${ }^{7}$ Ao final do texto "Inventário do Museu do Ben" onde todas as peças contidas na caixa são listadas há a informação "[...] uma idéía a mais: sua leitura".
} 
Ben Vautier repousava sob cúpula de acrílico impedindo a manipulação e real conhecimento/interação com os objetos dados nessa obra crítica ao museu e estava desprovido de transcrição do texto em francês para compreensão do visitante brasileiro, enquanto as propostas de Takako Saito (somente expostas em Curitiba) eram vista pelo público como algo incogruente a exposição de arte. Para convidar à participação, abaixo das placas de metal havia mensagem "Favor tocar". Já neste último exemplo, apesar do conceito da obra (original em inglês emoldurado) estar traduzido em etiqueta, ainda os poucos bilhetes escritos eram recolhidos pelo educativo do museu para arquivamento e assim não se configurava de fato a proposta da obra, ou seja, troca, contato e comunicação.

Expostos de modo asséptico, num local idealizado onde quaisquer interferências são disfarçadas quando não eliminadas, uma exposição quase 'hospitalar' (salas de mínima interferência e preparadas para não interferir nas obras herdeiras do que se chamou "cubo branco"; opção vista nas salas expositivas do Museu Oscar Niemeyer) ou convivendo junto a loja, restaurante e saguões com elevadores para acesso aos piso empresariais (caso do Instituto Tomie Ohtake) se impede a fruição e por conseguinte os contágios entre arte e público, reforçando quão distante se quer o participador (anteriormente incorporado como elemento da obra). Deste modo a proposta poética não se dá: Fluxus não pode ser recuperado sem experimentação (ao menos mental), o visitante não conhece de fato os questionamentos colocados ou mesmo pode conferir semelhanças entre Arte e (sua) Vida. A 'nobre intenção' de ser ousado mostrando a produção dos anos 1960 e 1970 transforma-se em oferta ao 'gabinete de curiosidades' onde, por mais que textos indiquem importâncias históricas e artísticas, se apresenta o exótico, o que (realmente) está distante.

O público incorporando essa assepsia fica fisicamente isolado por anteparos como vitrines, bases, faixas de distanciamento, alarmes e seguranças patrimoniais e, acostumado neste isolamento que não consegue competir com os estímulos plurisensoriais oferecidos pela tecnologia e mostras 'blockbuster' se tornou um 'voyeur' da arte.

No intuito de oferecer a produção artística legitimada ao público, os museus e suas exposições optaram por expografias de impacto para tirar seus 'clientes' da habitual anestesia. Mostram obras ladeadas por textos

${ }^{8}$ In: O'DOHERTY, Brian. No interior do Cubo Branco: a ideologia do espaço da arte. São Paulo: Martins Fontes, 2005. p. 23. 
explicativos e monitores - dinâmica que legitima novamente os trabalhos ali expostos conferindo-lhes o status de objetos artísticos, quiçá patrimônio a ser eternizado, mas também reforçam o status do próprio museu e sua tarefa sócio-cultural de acolher a produção artística garantindo sua perenidade. Mas isto, que soma às obras palavras daqueles que regem as instituições, nem sempre condiz com aquilo que deveria chegar ao visitante - são discursos depositados sob às obras que chegam mesmo a mudar totalmente seu(s) significado(s) ${ }^{9}$.

Indiretamente permanece neste contexto o modelo de museu ancorado nos gabinetes de curiosidades e nas idéias do Iluminismo, onde a classificação proporciona rotulações e taxonomias para conseqüente exposição e preservação das peças. Essas narrativas conservadoras, tentando se respaldar nas noções difundidas e aceitas de arte e história da arte, dividem e classificam os trabalhos expondo-os geralmente numa estrutura cronológica ou temática. O museu arranca os objetos de seus entornos originais não somente como ato de celebração política mas com o objetivo de criar a ilusão de um conhecimento universal, de expor um contínuo remodelado da história fetichizando seu acervo ${ }^{10}$.

Se os museus estariam deturpando obras de arte ao mesmo tempo em que se fortaleceram na posição de detentores das manifestações culturais (missão cuja tendência é permanecer, uma vez que essa atribuição já se consolidou anteriormente quando as antigas coleções privadas tornaram-se públicas sendo expostas e formando os acervos dos primeiros museus); poderiamos ainda encontrar arte e história em suas mostras? Ou o encontro é de resíduos de produção artística, sob discurso dos que legitimam, a um público anestesiado? Ainda pode-se conseguir comunicação por meio de acervos e suas mostras?

Assim como ocorre na produção artística, os museus precisam olhar para si e se reavaliarem constantemente. Algumas produções

\footnotetext{
${ }_{9}^{9}$ Douglas Crimp descreve sua surpresa ao encontrar a obra de Ed Ruscha, Twentysix Gasoline Stations (1962) junto ao acervo da biblioteca do MOMA (Museum of Modern Art; Nova Iorque) ao invés desta estar classificada como acervo artístico. (CRIMP, Douglas. Sobre as ruínas dos museus. São Paulo: Martins Fontes, 2005. p.71)

${ }_{10} \mathrm{O}$ MOMA ao trabalhar com acervo preponderantemente de arte moderna, chegou a declarar à imprensa que não pretende meramente apresentar objetos individuais da arte moderna ma, em vez disso, uma narrativa da história desses objetos. Narrativa esta que pode ter construção enganosa porém apropriada à frase que desejam expor para o visitante. Para tal também domesticam as obras da vanguarda soviética, de Duchamp e dos dadaístas alemães, apresentando-as como obras-primas convencionais das belas-artes e distorcendo as implicações radicais dessas produções. (Op. Cit. p.232).
} 
contemporâneas são bons instrumentos para ajudar nesse exame e os artistas podem indicar alternativas ou práticas que mais se adequam a exposição da arte contemporânea de modo para que esta não perca suas potencialidades ao encontro com o público - o que consequentemente ofereça futuras leituras, talvez menos impregnadas de histórias préconcebidas e mais amparadas em sinestesias, e assim a herança cultural possa ser compreendida de modo aberto e livre a outras novas conexões e circulação.

\section{Bibliografia}

CRIMP, Douglas. Sobre as ruínas dos museus. São Paulo: Martins Fontes, 2005.

FREIRE, Cristina. Afasias na crítica de arte contemporânea. Os lugares da crítica de arte. São Paulo:ABCA/ Imprensa Oficial do Estado, 2005. p.63 a 75.

HENDRICKS, Jon. O que é Fluxus? O que não é! O porquê. Rio de Janeiro: Centro Cultural do Banco do Brasil, 2002.

O’DOHERTY, Brian. No interior do Cubo Branco: a ideologia do espaço da arte. São Paulo: Martins Fontes, 2005.

ZELLER, Ursula (org.). Fluxus in Germany 1962 - 1994. A long tale with many knots. (catálogo de exposição). Stuttgard: The Institut für Auslandsbeziehungen, 2005. 